\title{
CARACTERIZAÇÃO DA LAMA DE ALTO-FORNO DE UMA SIDERÚRGICA INTEGRADA DO SUDESTE DO PARÁ *
}

\author{
Wellington Bruno Silva de Jesus ${ }^{1}$ \\ Alacid do Socorro Siqueira Neves ${ }^{2}$ \\ Emanuel Negrão Macêdo ${ }^{3}$ \\ José Antônio da Silva ${ }^{4}$ \\ Luiz Felipe Silva Pereira ${ }^{5}$ \\ Roseane de Lima Silva ${ }^{6}$ \\ Verônica Scarpini Cândido ${ }^{7}$
} Resumo

O Alto-Forno é o principal equipamento em uso para a produção do ferro gusa. Para a redução do minério de ferro em gusa são alimentados pelo topo do alto forno a carga composta por minério de ferro, carvão vegetal ou coque e calcário. Durante o processo de redução os gases redutores ascendentes entram em contato com a carga e geram pós no interior do alto forno. Para que esse resíduo não seja lançado diretamente na atmosfera é necessário que haja a recuperação desse material particulado e uma das etapas é a lavagem da poeira do gás de alto-forno que permite a separação dos particulados sólidos na forma de lama, denominada lama de alto-forno. O objetivo do presente trabalho é a caracterização físico e química da lama do alto-forno a carvão vegetal de uma siderúrgica integrada localizada na região sudeste do estado do Pará, e assim fornecer subsídios para estudos que busquem o reaproveitamento desse resíduo através da sinterização para torná-lo um material mais reativo e dar uma destinação ecologicamente correta e de acordo com as normas ambientas. Para isso, foram realizadas, em laboratório, análises como a granulometria, massa específica, difratometria de raios - $x$ e fluorescência de raios x. Os teores dos óxidos predominantes foram $57,33 \%$ de $\mathrm{Fe} 2 \mathrm{O} 3,8,14 \%$ de $\mathrm{CaO}$, $5,6 \%$ de $\mathrm{SiO} 2$ e $1,37 \%$ de $\mathrm{ZnO}$ ).

Palavras-chave: Lama de alto-forno; Caracterização química; Resíduo.

\section{CHARACTERIZATION OF THE HIGH-OVEN MUD OF AN INTEGRATED SOUTHERN STEEL FROM PARÁ}

\section{Abstract}

The Blast Furnace is the main equipment in use for the production of pig iron. For the reduction of iron ore in pig iron are fed charged by the top of the blast furnace the cargo charge composed of iron ore, charcoal or coke and limestone. During the reduction process the ascending gases of reduction come in contact with the charge and generate powders inside the blast furnace. In order for this residue not to be released directly into the atmosphere, it is necessary to recover this particulate material and one of the steps is to wash the dust from the blast furnace gas, which allows the separation of the solid particulates in the form of sludge, The objective of the present work is the physical and chemical characterization of a blast furnace sludge from an integrated steel mill located in the southeastern region of the state of Pará, and thus provide subsidies for studies that seek the reuse of this residue through sintering to Make it a more reactive material and give an ecologically correct destination and according to environmental standards. For this, analyzes such as granulometry, specific mass, $x$ - ray diffractometry and $x$ - ray fluorescence were performed in the laboratory. The predominant oxides contents were $57.33 \% \mathrm{Fe} 2 \mathrm{O} 3$, $8.14 \% \mathrm{CaO}, 5.6 \% \mathrm{SiO} 2$ and $1.37 \% \mathrm{ZnO}$ ).

Keywords: Blast Furnace Sludge; Chemical Characterization; Residue. 
1 Engenharia de Materiais, Graduando, Pesquisador, Faculdade de Engenharia de Materiais, Universidade Federal do Pará, Ananindeua, Pará, Brasil.

2 Engenheiro Químico, Mestre em Engenharia Química, Pesquisador Doutorando, Professor e Diretor, Faculdade de Engenharia de Materiais, Universidade Federal do Pará, Ananindeua, Pará, Brasil.

3 Engenheiro Químico, Doutor em Engenharia química, Professor, Faculdade de Engenharia Química, Programa de Pós-graduação de Engenharia de Recursos Naturais da Amazônia da Universidade Federal do Pará, Belém, Pará, Brasil.

4 Engenheiro Químico, Doutor em Engenharia química, Professor, Faculdade de Engenharia Química, Programa de Pós-graduação de Engenharia de Recursos Naturais da Amazônia da Universidade Federal do Pará, Belém, Pará, Brasil.

5 Engenheiro Químico, Mestre em Engenharia Química, Pesquisador Doutorando, Programa de Pós-graduação de Engenharia de Recursos Naturais da Amazônia da Universidade Federal do Pará, Universidade Federal do Pará, Belém, Pará, Brasil.

6 Engenheira Química, Doutora em Engenharia Mecânica, Professora e Diretora, Faculdade de Engenharia de Materiais, Universidade Federal do Pará, Belém, Pará, Brasil.

7 Biologia, Doutora em Ciência dos Materiais, Professora, Faculdade de Engenharia de Materiais, Universidade Federal do Pará, Ananindeua, Pará, Brasil. 


\section{INTRODUÇÃO}

Atualmente são gerados grandes quantidades de resíduos no setor siderúrgico, e esses resíduos na sua grande maioria não tem um destino e um tratamento adequado, o que vem de certa forma gerar custos a indústria com esse descarte. De acordo com Almeida e Melo (2001) um dos grandes problemas dos resíduos está na forma de gerenciamento, sendo que uma parte significativa das indústrias independentes de gusa não dispõe de dados relativos à caracterização dos resíduos e, em geral, não existe uma preocupação quanto à destinação ambientalmente adequada. Alguns estudos já realizados sobre o processo e a composição desses resíduos, em geral eles apresentam grandes quantidades de metais pesados, o que requer não só o aprofundamento de estudos sobre os mesmos mas também novas descobertas sobre esse tipo de material. Mas a grande questão é o que se fazer com esse material, ou seja uma forma de gerenciamento que venha a ter um retorno positivo a indústria, dando a destinação e o tratamento correto a esse material dentro da própria siderúrgica e que venha a trazer benefícios a indústria. Então ter o domínio e conhecimento da caracterização desse tipo de resíduo é de suma importância para se chegar a um método de aproveitamento de forma ambientalmente correta. Em uma siderúrgica o equipamento mais importante é o alto forno, e claro o responsável pela geração de resíduos como; a poeira, a escória e a lama de alto forno. Essa lama é obtida através do processo de lavagem da poeira do gás de alto forno e separação de particulados sólidos. Por fim, o presente trabalho mostra a caracterização química da lama de alto forno de uma siderúrgica integrada no sudeste do Pará com finalidade de fornecer embasamento para possíveis aplicações de acordo com as leis que regem a preservação do meio ambiente e claro beneficiar a industrial.

\section{MATERIAIS E MÉTODOS}

Foi utilizada uma amostra de poeira de aciaria elétrica, gentilmente, cedida pela SINOBRAS, siderúrgica integrada, em Marabá, município localizado no sudeste do Pará. Inicialmente realizou-se análise química visando a determinação de teor de umidade e massa específica do resíduo, seguida das análises granulométrica, difração de raio - $X$ e florescência de raio - $X$.

Para a verificação de teor de umidade foram colocados $150 \mathrm{~g}$ de lama de alto forno para secar por 24 horas á $105^{\circ} \mathrm{C}$ na estufa, depois pesou-se a massa seca e por diferença de massa, obteve- se o teor de umidade. Em seguida foi determinado a massa específica da lama de alto forno através da média de três amostras do material, utilizando o álcool como fluido por ter menor densidade que a água destilada. Já na análise granulonométrica foi utilizado um jogo de peneiras de Tyler $(14,28,48,100,150,200$ e 270) e feito o peneiramento

por 20 minutos. Por fim foi feita a difração de raio- $x$ (DRX) no laboratório ig/UFPA com o aparelho difratrometro X'per Rt MPD-PRO Panalitycal e a florescência de raiox (FRX) em um espectrômetro X epsilon 3, marca Panalitycal.

\section{RESULTADOS E DISCUSSÃO}

Após as análises realizadas foram obtidos os resultados de teor de umidade, que chegou a $0,451 \mathrm{~g}$ de perda de umidade, ou seja aproximadamente $31 \%$ de perca de massa de água, o que podemos dizer ser um valor relativamente baixo, 
comparados a amostras de outros estudos. A massa específica foi de 0,642, valor da média de massa específica de três amostras. A tabela 1 a seguir mostra os resultados obtidos na florescência de raio $-x$, que entre os vários óxidos, foi observado os maiores teores de $\mathrm{Fe} 2 \mathrm{O} 3, \mathrm{CaO}$ e $\mathrm{ZnO}$. Os teores apresentados foram determinados por análise sem padrões (standardless) de elementos químicos de sódio a urânio, em espectrômetro por fluorescência de raio X Epsilon 3, marca panalytical.

A figura 1 mostra a análise de difração de raio- $x(D R X)$ onde podemos observar picos de alguns óxidos como hematita $\mathrm{Fe} 2 \mathrm{O} 3$, calcita $\mathrm{CaCO} 3$, quartzo $\mathrm{SiO} 2$, magnetita $\mathrm{Fe} 3 \mathrm{O} 4$ e wustita $\mathrm{Fe} 9712 \mathrm{O}$, com os maiores picos de hematita, havendo também outras fases cristalinas minoritárias. E a figura 2, temos o gráfico da granulometria, onde temos o percentual de material retido, onde a maior quantidade de material retido se concentra .

Tabela 1. Florescência de Raio $X$

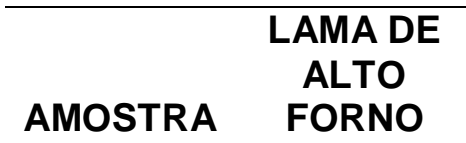

\begin{tabular}{lc}
\hline $\mathrm{Na}_{2} \mathrm{O}$ & 0,45 \\
\hline $\mathrm{MgO}$ & 0,61 \\
\hline $\mathrm{Al}_{2} \mathrm{O}_{3}$ & 0,35 \\
\hline $\mathrm{SiO}_{2}$ & 5,60 \\
\hline $\mathrm{P}_{2} \mathrm{O}_{5}$ & 0,20 \\
\hline $\mathrm{SO}_{3}$ & 0,82 \\
\hline $\mathrm{Cl}$ & 0,65 \\
\hline $\mathrm{K}_{2} \mathrm{O}$ & 0,55 \\
\hline $\mathrm{ZnO}$ & 1,37 \\
\hline $\mathrm{CaO}$ & 8,14 \\
\hline $\mathrm{TiO}_{2}$ & 0,38 \\
\hline $\mathrm{Cr} \mathrm{O}_{3}$ & 0,04 \\
\hline $\mathrm{MnO}$ & 0,79 \\
\hline $\mathrm{Fe}{ }_{2} \mathrm{O}_{3}$ & 57,38 \\
\hline $\mathrm{CuO}$ & 0,03 \\
\hline $\mathrm{Br}_{\mathrm{ZrO}}$ & 0,06 \\
\hline $\mathrm{PbO}$ & 0,03 \\
\hline
\end{tabular}

Valores expressos em \% de óxidos, normatizados a $100 \%$ 


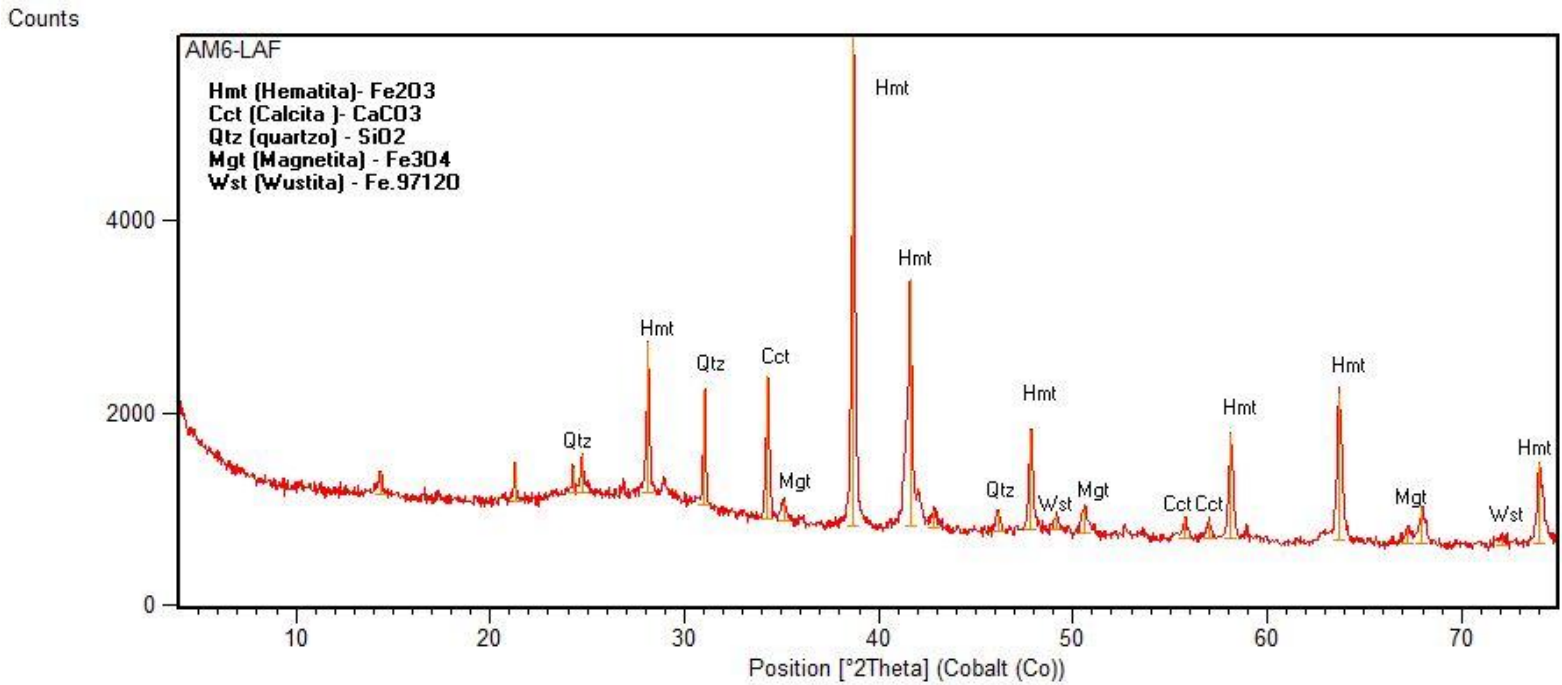

Figura 1. DRX

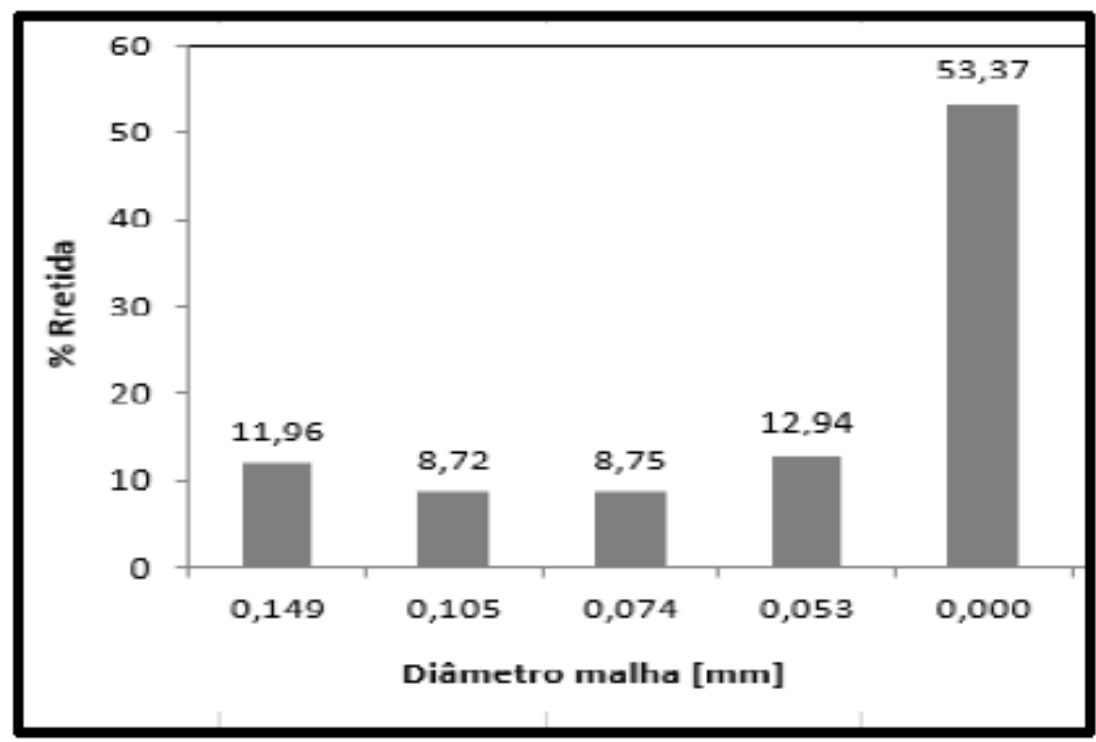

Figura 2. Granulometria

\section{CONCLUSÃo}

A caracterização química da lama de alto forno foi satisfeita e podemos constatar um valor não muito elevado de teor de umidade, na sua composição química temos predominante de dióxidos de ferro, hematita, calcita, magnetita, quartzo e wustita. Essas características dificultam o processo de reaproveitamento deste resíduo em várias áreas.

As análises de DRX e FRX mostraram a quantidade e variedade de metais pesados que contém a lama, onde podemos destacar no DRX na figura 1, a maior predominância de hematita. Através gráfico da granulometria, figura 2 podemos observar sua fina granulometria, tornando-o um resíduo complexo, mas por outro lado, foi possível a obtenção de propriedades como as altas taxas de ferro que indicam a possibilidade de reaproveitamento do subproduto no próprio alto-forno, na forma de briquetes e em industrias cerâmicas. 


\section{REFERÊNCIAS}

Vieira CMF, Dias CAC M, Monthé AV, Sánchez R, Monteiro SN. Incorporação de lama de alto forno em cerâmica vermelha Cerâmica 53 (2007) 381-387.

Oliveira FR (UFOP) ; Silveira CS (UFOP) ; Assis PS (UFOP). Caracterização química e estudo de possíveis aplicações para a lama gerada em alto-forno.

Dalvan PIG, Reinert J, Reichert JM. Método alternativo para a determinação da densidade de partículas do solo - exatidão, precisão e tempo de processamento, Ciência Rural, Santa Maria, v.36, n.2, p.664-668, mar-abr, 2006

Silva GV, nascimento RC. Reciclagem de resíduos sólidos siderúrgicos via processo de sinterização. Ln: xi congresso nacional de meio ambiente de poços de caldas.

Neves, A.S.S. (UFPA) ; Daniel, B.T.F. (UFPA) ; Souza, J.A.S. (UFPA) ; Quaresma, D.S. (UFPA) ; Pereira, L.F.S. (UFPA) ; Macedo, E.N. (UFPA) ; Silva, M.V.R. (UFPA) ; Dias, L.M.M. (UFPA). $56^{\circ} \mathrm{CBQ}$ - Caracterização física e química da carepa de laminação para estudo em sinterização.

Araújo, Luiz Antonio de. Manual de siderurgia $-2^{\circ} e d$. São Paulo: Arte e Ciência editora, 2005 